\title{
Systems Informed Positive Education
}

\author{
Margaret L. Kern and Jessica A. Taylor
}

The year 2020 was a year like no other. It began with massive bushfires consuming the Australian bushlands, destroying communities, with countless species driven to extinction. Climate change took central focus-surely that would be the big story and battle of the year. But even as smoke and flames still covered a drought-stricken land, China went into hard lockdown, as a novel coronavirus rippled out from marketplaces in the city of Wuhan. In a globalised world, the coronavirus rapidly spread, quickly becoming a global problem. Cities worldwide entered into varying levels of government-imposed restrictions. At first, there was collective nervous energy as people tried to navigate uncertainty. Store shelves were emptied of toilet paper and other commodities. Homes were converted into home offices. Teachers rapidly upskilled, creatively finding ways to teach online. Parents came face-to-face with the challenges that educators deal with every day as families tried to manage home learning. The changes were challenging to navigate, but the pain would be short-lived, and then life would return to normal. But case numbers kept growing, death counts rose. As weeks turned to months, economies buckled, mental health issues grew, exhaustion set in, tensions rose. The Black Lives Matter movement in the U.S. resulted in calls for systemic change in the U.S. and abroad. Conspiracy theories and misinformation festered through online networks, resulting in growing mistrust, polarisation, and uncertainty.

M. L. Kern $(\varangle) \cdot$ J. A. Taylor

University of Melbourne, Melbourne, VIC, Australia

e-mail: Peggy.Kern@unimelb.edu.au 
Schools were at the frontline, becoming a battleground that illustrated the deep flaws embedded within many schools and systems. The novel coronavirus continually brought a number of complexities and surprises. Children seemed to be unaffected, but potentially could spread the disease, or might experience longer term consequences that are yet to be identified. Immediate questions arose. We needed to keep workforces running-how could people work if they also had to supervise home learning? Schools provide not only academic skills, but important non-cognitive skills, including social and emotional competencies and character development. What happens when that training is rapidly shifted back to parents, many of whom lack their own capabilities? A growing number of equity issues emerged, with some learners having ready access to technology and support from caring parents, while others lacked technology, disengaged with learning, or experienced home as an unsafe place. Teachers went far beyond expectation to support their students, teach academic skills, and manage the various pressures from students, parents, co-workers, leaders, and the broader society. Some teachers, students, and families coped well; others languished. As societies began to reopen, teachers were expected to return, supporting others, pressing on with imparting knowledge, all the while feeling exhausted, overwhelmed, fearful, and far too often under-valued and under-supported.

These tensions give light to long-held societal assumptions that pervade many school systems worldwide, including siloed thinking, the tightly held economic importance and expectations that are placed on academic achievement, accreditation and grading systems that act as a gateway to the future, unrealistic expectations and demands on staff to pivot without necessary upskilling and support, and disparities of resources. The challenges are daunting. They reveal broken systems and the need to rethink our approaches to education, mental health and wellbeing, equity, support, and the many complexities of the twenty-first-century world.

Within this landscape, mental health and wellbeing has increasingly come to the forefront, with many people not coping well. Before 2020, wellbeing was increasingly permeating policies, infrastructures, and applications (Biswas-Diener, Diener \& Lyubchik, 2015; Buckler \& Creech, 2014; Harrison et al., 2016), with schools seen as an ideal platform for mobilising wellbeing initiatives that aim to support individuals, communities, and societies (Organisation for Economic Co-operation and Development [OECD], 2018). As societies worldwide attempt to emerge from the COVID-19 pandemic, placing wellbeing at the centre of education becomes more critical than ever. 
Positive education, with a direct focus on understanding and cultivating wellbeing, is well situated to contribute to this space, but must carefully consider what that contribution ought to be. Over the past decade, a growing number of schools have incorporated positive education into curricula, cocurricular activities, pastoral care, and other areas of the school. Some have even labelled themselves as "positive education schools". Too often, positive education is presented as a specific model, program, or curriculum, with simplified activities that attempt to teach students and staff the skills and knowledge of wellbeing by focusing on isolated features, such as gratitude or mindfulness. Arbitrary distinctions are made between positive education programs, social and emotional learning (SEL), character education, holistic education, positive behavioural interventions and supports (PBIS), etc., such that programs are pitted against one another and schools pass from one program to the next or add additional initiatives to already over-crowded curricula. This can result in considerable activity with little impact (White $\&$ Kern, 2018).

The year 2020 accentuated the massive economic, social, psychological, political, equity, ethical, and ecological challenges facing our world, as well as the intricate interconnectedness of these challenges. Despite desires for simple solutions and quick fixes, our plans and solutions fail in light of the complexities of the issues we face (Nguyen \& Bosch, 2013). Schools comprise multiple interconnected components, including students, teachers, parents, curriculum, legislation, policy, and funding, all of which intersect with the broader challenges and opportunities facing the world. We contend that for wellbeing initiatives to be successfully embedded within our school systems, we must approach wellbeing as a coordinated effort that involves seeing and sensing the whole system, along with the interrelationships and interdependencies amongst each element.

We suggest that for positive education to progress and truly create the impact that many educators envision, a systems informed positive education (SIPE) perspective is needed. SIPE explicitly incorporates aspects of the systems sciences into positive education practice and pedagogy to cultivate optimal learning environments that bring out the best in each individualincluding students, teachers, staff members, school leaders, parents, and others who may be a part of, connected with, impact upon, or impacted by that community - and of the school community as a whole. In this chapter, we introduce the SIPE perspective. We highlight key principles and their application in schools. We provide several case studies, illustrating SIPE in action. We end with implications for embedding wellbeing as a lasting endeavour that becomes deeply woven within the fabric of education systems. 


\section{Positive Education: Activity or Impact?}

Over the first two decades of the twentieth century, there was exponential growth in research and practice around positive education (Slemp et al., 2017; White \& Kern, 2018). The interest and excitement arose in part from the optimistic hope that positive education would become the next approach to fix the woes of education, and would provide a quick fix to both flailing academic scores and the growing mental health crisis. Yet while the excitement for positive education is commendable, there is danger in the field moving too quickly, practice far outstepping the research, and the movement as a whole becoming yet another passing educational fad, rather than a perspective and approach that transforms education to bring out the true potential of everyone within the educational community and beyond.

Clearly, as evidenced throughout this Handbook, there are numerous perspectives on and approaches to positive education. From our experience in Australia, positive education is often presented as a specific positive psychology-informed curriculum (i.e., positive psychology applied to education); as programs focused on specific topics (e.g., positive emotions, gratitude, mindfulness), often centred around a framework or model (which may or may not be appropriate for the specific needs of the school); or as a focus on the wellbeing of the individual student (and at times staff), rather than each of these elements as interconnected contributors to the broader systems in which they are embedded. While interventions from positive psychology can be useful and building upon existing research provides a helpful starting point, simple interventions and prescriptive programs often fail when incorporated within the complexities of classrooms, schools, and broader educational systems. Each student's experience of and interpretation around a positive intervention is impacted by their personality; social context; history and experiences at home, with peers, and across school settings; how the intervention or program is taught; along with a myriad of other factors.

Additionally, despite operating in a rapidly changing world, most educational institutions have remained organised and function as they have for decades, with rigid structures that often lack the flexibility and adaptability needed in the modern world (Garmston \& Wellman, 1995). Demands on learners and education systems are rapidly evolving. Students today are growing up in an increasingly volatile, uncertain, complex, and ambiguous world (Fadel, Bialik, \& Trilling, 2015). Demands are rising for schools to become learning organisations that not only acknowledge the complexities of today's world, but also help students learn the skills, knowledge, and capabilities that can help them make meaningful contributions within the complex 
interdependent systems in which they are situated (Goleman \& Senge, 2014; Senge, Cambron-McCabe, Lucas, Smith, \& Dutton, 2012). It is no longer sufficient for schools to focus solely on reading, writing, and arithmetic; to teach discrete skills to solve disassociated problems; or to have standalone processes and knowledge for how to achieve wellbeing.

The world, and thus students today, faces global challenges that require global solutions, and education must provide opportunities for students to develop and build the awareness, understanding, capabilities, skills, and values to engage in resolving the many interconnected challenges of the twenty-first century (Global Education Leader's Program, 2013; OECD, 2018). We need to ask what education for an emerging and preferred future looks like for students, teachers, schools, and society as a whole. We suggest that there is a need to look beyond existing paradigms and structures to learn from and with the systems in which young people are embedded, their interrelationships and interdependencies, and our responsibilities of nurturing and understanding the interconnectedness of self, school, society, and the world as a whole.

\section{Towards a Systems Informed Approach to Positive Education}

A system refers to a group of things that are interconnected in some manner (Senge et al., 2012). For example, a school is a system that includes students, teachers, administrative staff, leadership, and parents. A classroom is a system that includes students and teachers. Systems are all around us, and range from very small (e.g., the human body) to very large (e.g., a regional school district). The systems sciences study, model, and intervene upon systems (Hieronymi, 2013). Applying a systems perspective to positive psychology theory, research, and practice, Kern et al. (2020) suggested Systems Informed Positive Psychology (SIPP) as an evolution to traditional positive psychology, which explicitly incorporates aspects of systems science into positive psychology theory, methodologies, and discourse, so as to optimise human social systems and the individuals within them. SIPE applies this perspective specifically within education. Drawing upon the many systems elements and concepts the systems sciences have identified, SIPP identified several key systems elements that are particularly relevant for considering human flourishing and proposed a set of principles to guide positive psychology theory, research, and application. Here we briefly describe the 
key elements and principles, pointing to how the SIPP principles appear in schools, before turning to case studies that illustrate SIPE in action.

\section{Key System Elements}

There are multiple elements of systems that inform the SIPP perspective. First, different elements within the system interact and align, such that together they are different than any single part alone (Meadows, 2008). For example, reflecting on three good things that happened during the day might look very different in a personal reflection journal, versus sharing those things with a class, where you are trying to maintain a particular social identity.

Second, individuals within the system often have different perspectives, which they bring to any situation, behaviour, or interaction (Jackson; 2003; Spencer, Dupree, \& Hartmann, 1997). Those perspectives are developed throughout life through biological tendencies, environmental influences, personality characteristics, personal and social experiences, and a person's interpretations and understanding of those experiences (Spencer et al., 1997). Thus, two people with similar histories and backgrounds can experience the same situation in very different ways. This has several implications. There is a need to acknowledge that different people see things in different ways, and one perspective is not necessarily better than another. There is a need to consider whose perspective is being included and who is excluded, and the impact those inclusions and exclusions might have. In addition, one's perspective in the future will be affected by the perspectives that were or were not included in the past. We are often most likely to listen to the voices that reaffirm existing beliefs. Shifting prior beliefs requires purposefully listening to diverse perspectives with open-minded curiosity (Scharmer, 2018).

Third, there are many different interrelationships within a given system. If a person engages in an action, it not only impacts that person, but also numerous other elements within the system. For example, Jane gives a flower to Chris. Jane might feel good about doing a kind act. Chris could feel appreciated, might feel pressured to reciprocate the act, or might wonder if Jane is trying to manipulate him. Other students might believe that Jane is being nice, they might feel jealous that she did not give them a flower, or they might tease her that Chris is her "boyfriend". Thus, while the simple positive psychology intervention of doing an act of kindness might be beneficial, it might also be problematic for that individual or for other individuals that are somehow impacted—positively or negatively—by that act. 
Fourth, every system has boundaries that are either explicitly or implicitly defined. Boundaries refer to what is in or out-what elements are considered to be a part of the system and what elements are outside of the system. For example, when we think about incorporating positive education within a school, we might draw the boundary of our system as a single classroom (which includes the students and the teacher), as a year level (which adds other classes), as a school (which adds staff and leaders at the school), as an educational community (which adds parents and the local community), or as a region (multiple educational communities across a state). Boundaries are fluid and temporary, but necessary to enable action. Where we draw that boundary impacts who and what we include in any intervention effort. For example, if we draw a narrow boundary - the classroom-then a teacher might plan a variety of activities to teach the students social and emotional skills. In contrast, if we draw a larger boundary-the whole school-then many more elements need to be included, such as varying student needs, staffing issues, funding, curricular demands, governance, and the climate of the school.

Fifth, systems are dynamic and ever-changing. Schools continually evolve over time, as staff and students come and go, leadership and policies change, curricula are introduced and retired, priorities shift, etc. Well-functioning systems adapt over time. The result that emerges might be quite different than the original vision but represents an adaptive shift over time. Positive education is never done, but rather needs to be an ongoing process that shifts and adapts to the dynamic changes that occur over time.

\section{SIPP Principles}

Drawing upon these elements, SIPP makes an underlying assumption that "humans inter-dependently co-exist with themselves, others, and the environment in which they exist" (Kern et al., 2020, p. 709). Thus, "values, activities, and ways of being must recognize and strive for environmental, social, and economic sustainability, which goes well beyond the individual" (p. 709). This assumption is complemented by three philosophical assumptions:

- Epistemological assumption: There is an objective reality, but there are no single objective vantages of that reality.

- Political assumption: Power, rights, and responsibilities are continually explicitly and/or implicitly negotiated, granted, and embodied by people within a system. 
- Ethical assumption: Wellbeing is defined in terms of virtuous we-being, striving towards what is collectively good, right, and optimal.

These assumptions result in a set of principles that, we suggested, should drive positive psychology theory, research, and practice. Table 5.1 summarises these principles, providing further explanations and examples of how they might manifest within schools.

We suggest, further, that a SIPE approach is more likely to be effective and sustainable than typical positive education approaches to education alone, as systems approaches take into consideration the complexity of a living system, and provides tools and strategies for bringing these complexities to light. Rather than positive education being a specific program applied within rigid and outdated school infrastructure, these principles provide fluid guidance for focusing positive education efforts on a contextually relevant, learnercentred, flexible, and adaptive approach that aims to bring out the full potential of every member of the educational community.

\section{SIPE in Action}

To bring SIPE to life, we briefly describe some inspiring examples occurring in schools and education systems worldwide that illustrate how the incorporation of systems thinking and principles might inspire future development and implementation endeavours for positive education.

\section{CASEL}

Although it is unclear at times whether SEL is part of or distinct from positive education, research on SEL programs provides the strongest support for focusing on non-cognitive skills in students (Durlak, Weissberg, Dymnicki, Taylor, \& Schellinger, 2011; Kern, Peterson, Park, \& Romer, 2017). SEL programs empower students to understand their emotions and social responses to the external world around them. Students learn to regulate their emotions; increase their attention; develop self-efficacy, self-awareness, and a sense of empathy for others; and improve social skills; helping to increase overall wellbeing, sense of belonging, and feelings about learning (Durlak et al., 2011; Oberle, Domitrovich, Meyers, \& Weissberg, 2016; Sklad, Diekstra, Ritter, Ben, \& Gravesteijn, 2012). While there is a diverse range of 


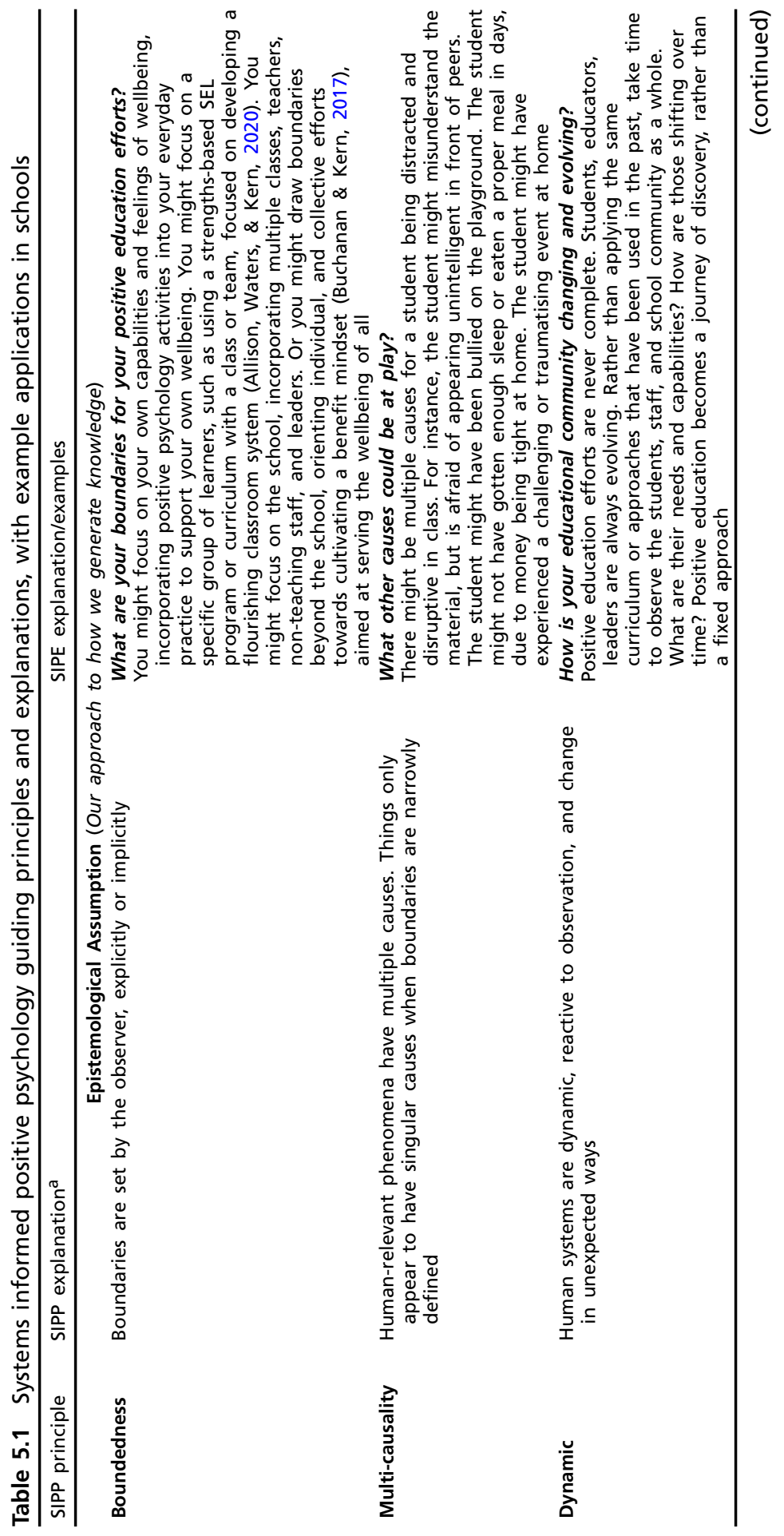




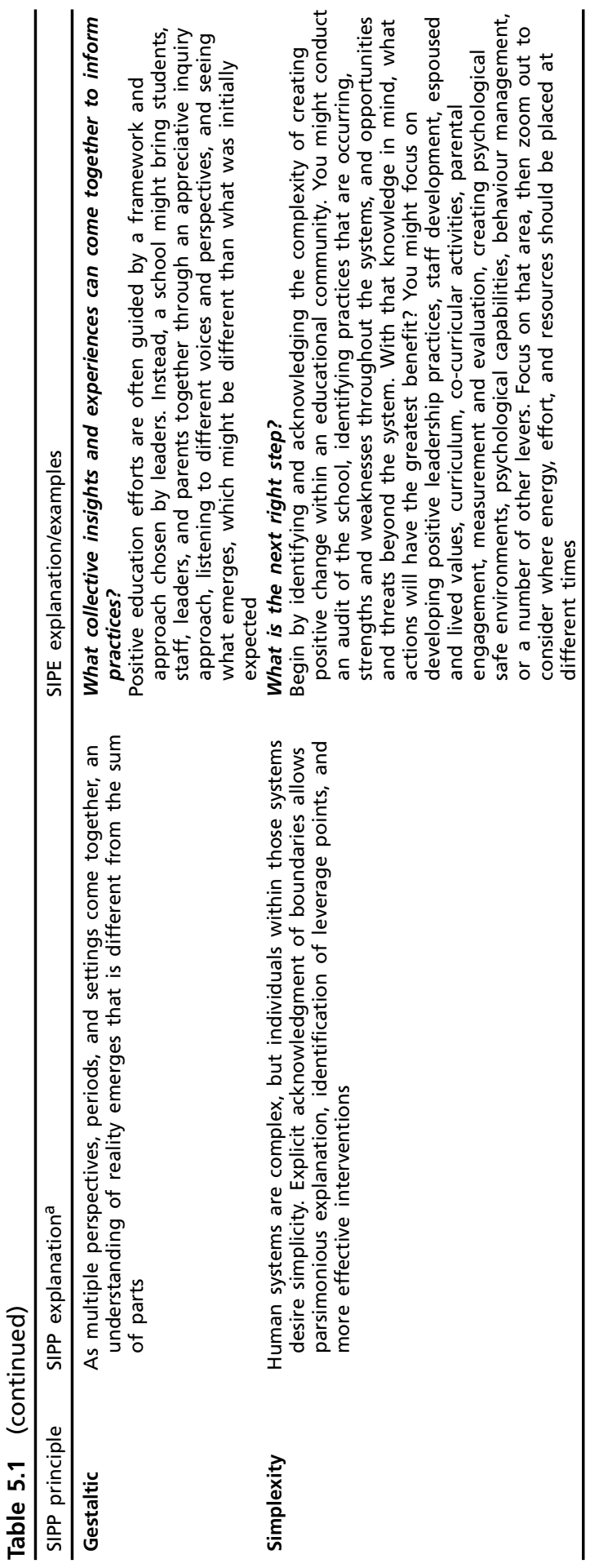




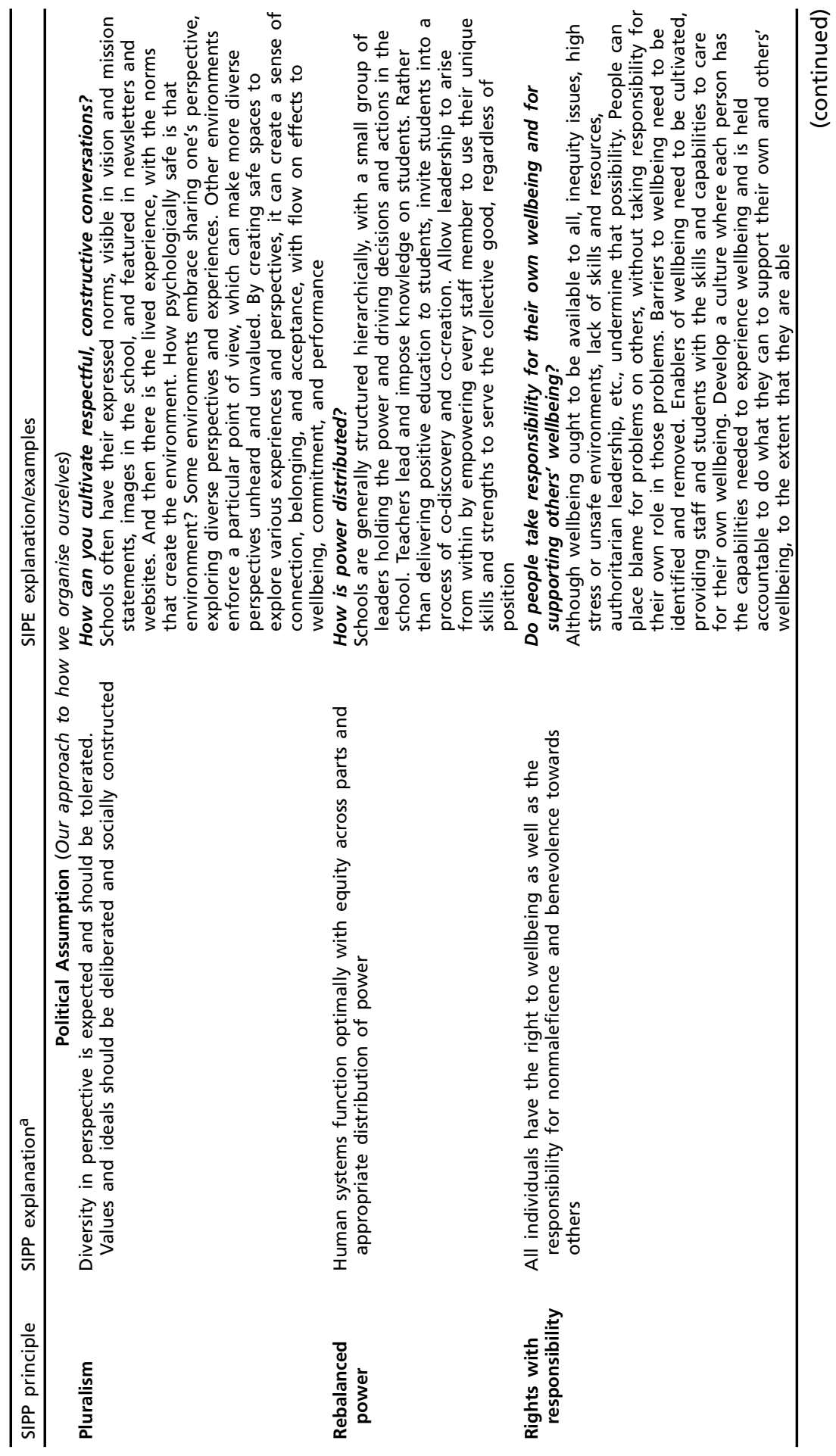




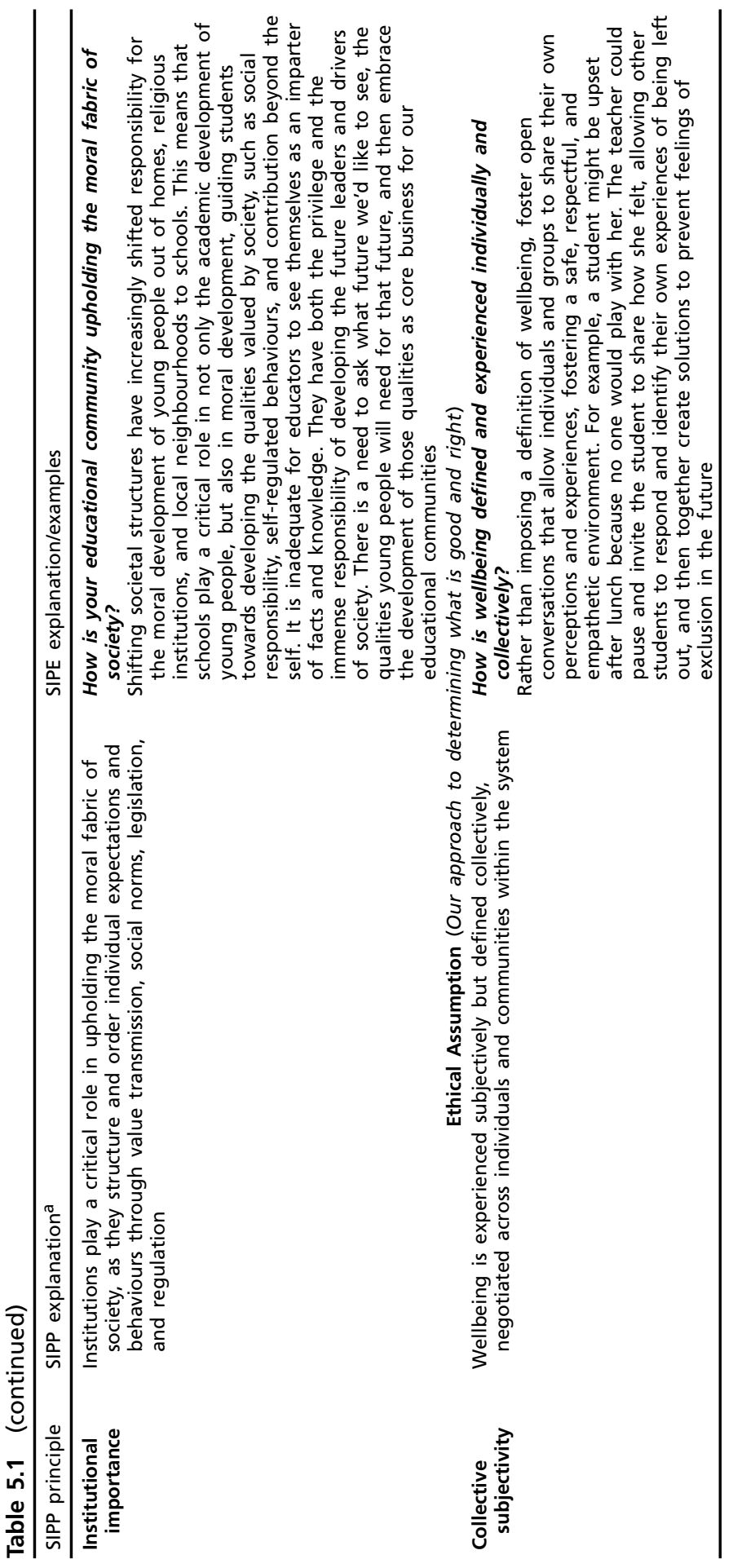




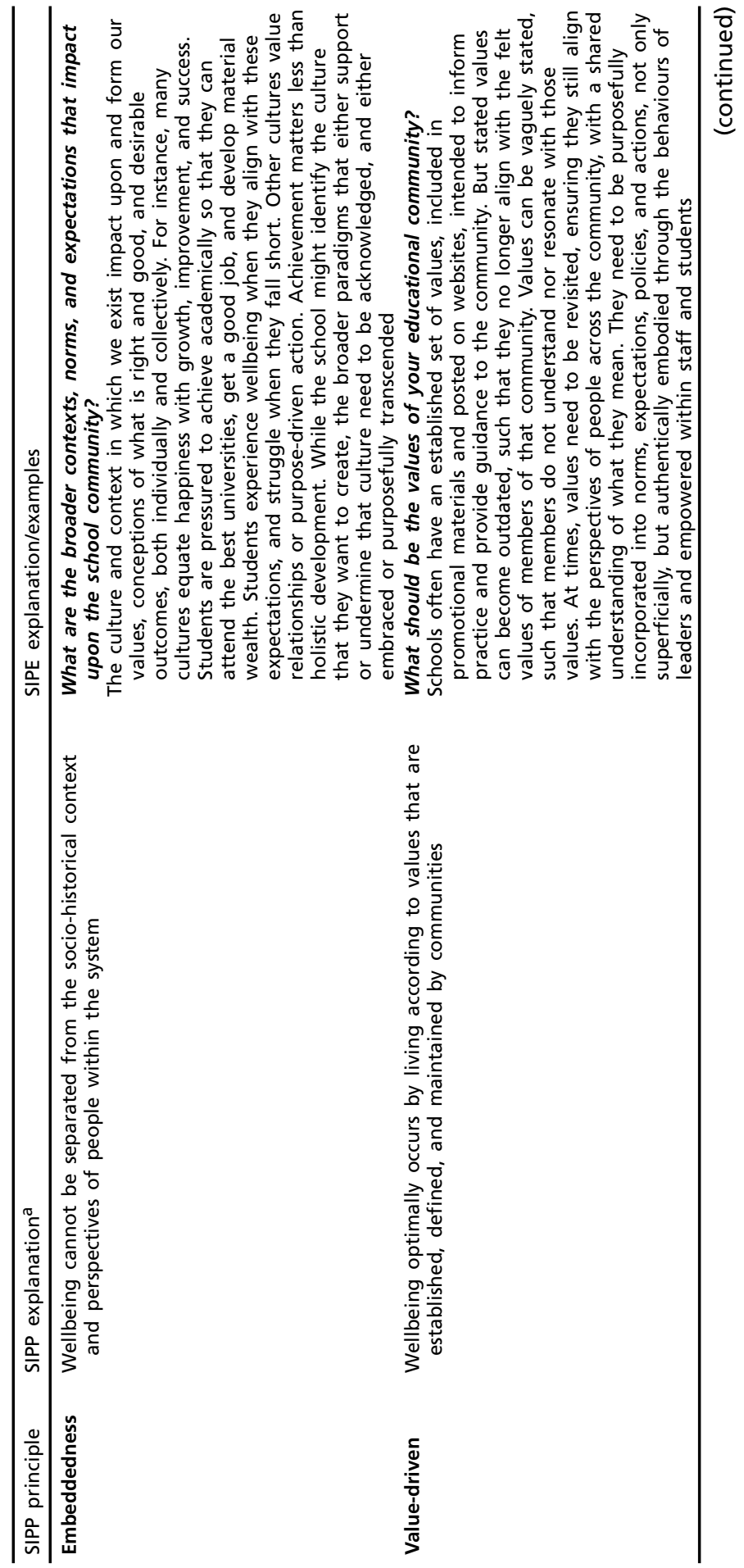




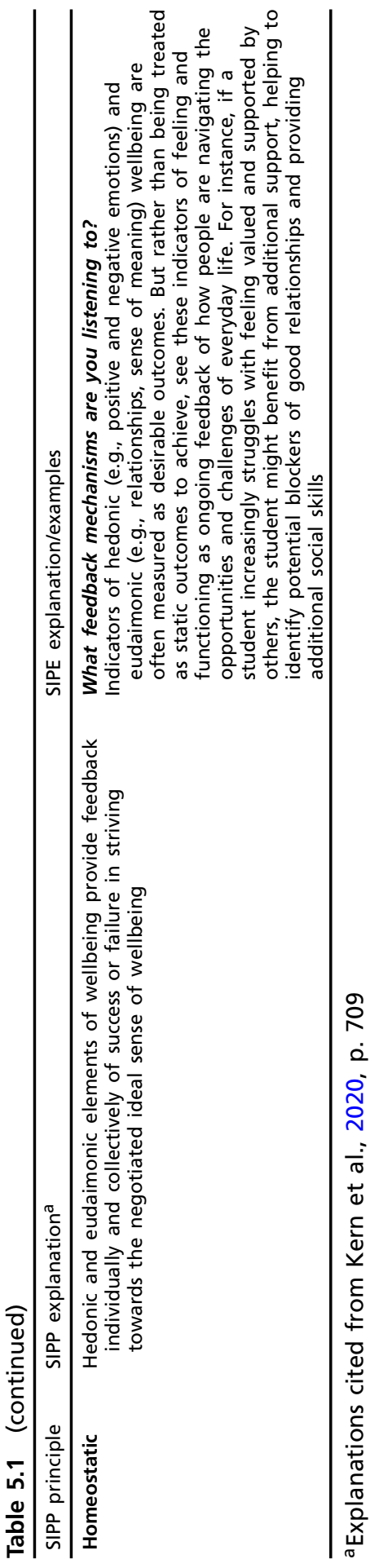


SEL-related programs and approaches, and the impact of SEL depends upon a range of implementation factors, as a whole, SEL programs have been found to successfully increase social and emotional skills, decrease anti-social behaviours, and correspond with better academic performance (Durlak et al., 2011; Kern et al., 2017).

The Collaborative for Academic Social and Emotional Learning (CASEL; www.casel.org) sits at the centre of many SEL efforts, providing an organising framework, priorities, and infrastructures to support related programs, curricula, and more. With the many schools and youth development programs inundating schools, CASEL adopted a systemic and systematic way to pull together relevant learning material and experiences that would develop a more holistic view of child health and wellbeing. Increasing social and emotional capabilities within a systems informed perspective not only helps students understand themselves as a system, but subsequently helps students understand the school system more broadly and assists them contribute move positively to society through building skills to help good decision-making for life. CASEL aims to make evidence-based SEL an integral part of education from preschool through high school, and is passionate about supporting systems transformation across the self, the school, and society as inter-related systems, endeavouring to educate hearts and inspire minds (Goleman \& Senge, 2014).

\section{Positive Youth Development}

Positive youth development (PYD) is a strengths-based approach to adolescence that arose from developmental systems theory (Lerner, Almerigi, Theokas, \& Lerner, 2005). In contrast to the often deficit-based view of adolescence, PYD sees adolescents as potential resources to be developed, with both youth and their contexts containing a number of strengths (Roth $\&$ Brooks-Gunn, 2003). There are dynamic interactions between the young person and their context, which are ever changing and evolving throughout adolescence. Healthy development is evidenced by engagement in meaningful activities that benefit others, contribution to one's community, and low engagement in risky behaviours. When the developmental assets of the person (e.g., commitment to learning, social and emotional competence, positive identity) are aligned with ecological assets (e.g., external supports, connections with peers and adults, constructive use of time, boundaries, and expectations), positive development is more likely to occur (Benson \& Scales, 2009; Larson, 2000; Lerner, Phelps, Forman, \& Bowers 2009; Vella, Oades, 
\& Crowe, 2011). PYD is committed to identifying and developing researchinformed policies that strengthen communities, the capacity of young people, and the fit between the two.

For example, the phenomenological variant of ecological systems theory (PVEST) is a PYD theory that builds upon Bronfenbrenner's (1994) socioecological systems model to understand stress and resilience during the course of adolescent development, taking into account not only the socio-historical context in which a young person develops, but also how that person's perceptions and appraisals that impact upon identity formation (Spencer, 1995; Spencer et al., 1997). PVEST emphasises a need to understand how young people perceive and interpret the people, opportunities, and experiences within their context; the structural and cultural factors that affect those perceptions; and the dynamic interactions amongst these elements. From this perspective, adolescents can experience the same event in completely different ways, depending on their own personality, previous experience, background, etc., resulting in maladaptive coping abilities, poor physical, mental, and social health, and deviant behaviours, or in competence, good health, and positive social outcomes. By understanding risk and protective factors, adaptive and maladaptive coping strategies, self-appraisal processes, and the dynamic interplay of different factors, it provides strategic opportunities for improving the long-term trajectories of young people at risk for poor developmental outcomes (Swanson, Cunningham, Youngblood, \& Spencer, 2008).

Such an approach might be used to understand a young person's context, including his or her interpretation of those experiences. The SIPE perspective would specifically emphasise protective factors, adaptive coping strategies, and positive self-appraisal processes that can be used as strengths within the system. Maladaptive patterns and risk factors are not ignored, and resources are given towards reducing problematic features, but comparatively greater focus is given towards positive aspects, shifting from a focus on mitigating risks to boosting capabilities. Interventions might focus on proactively strengthening the young person's psychosocial abilities, shifting personal narratives, providing programs that productively engage the young person's time and energy, and building resources in the local community.

\section{Schools that Learn}

Over the past several decades, Peter Senge, an influential thinker in the systems sciences, has called for schools to become learning organisations, where students, staff, and school leaders continually expand their capacity 
to create the results they truly desire, new and expansive patterns of thinking are nurtured, collective aspirations are set free, and where people are continually learning how to learn together. Here we point to several examples of schools that have embraced systems approaches in their contexts.

Orange Grove Middle School. Beginning in 1988, Orange Grove Middle School (https://ogms.cfsd16.org/), a private junior high school located in Tucson, Arizona, U.S., pioneered an alternative approach to learning that used systems thinking tools to engage in collaborative, real-world problem solving to hone students' critical thinking skills (Senge et al., 2012). The school incorporated a learner-centred approach aimed at helping students to connect and engage with school more deeply, foster habits of mind, and develop skills and motivations necessary to be leaders in today's complex world.

The first systems thinking classes were incorporated into the science curriculum, inviting students to design a new state park in the north part of the city. Through the project, students had to identify potential conflicts that could arise between park and wilderness management and other stakeholders. They used a systems dynamic computer software modelling program to create a simulation model of their designs. Not only did students engage with systems thinking approaches, but they also learned to think at a systems level as they explored the interdependency of economic, social, and ecological decisions and their subsequent consequences as they explored the complexity of the world as an interdependent system.

Senge et al. (2012) suggested that several elements helped students be immersed in their learning experience. First, students were engaged with realworld problems rather than conventional classroom exercises, making the learning meaningful and engaging. Second, there was no one right answer. Students were invited to think for themselves in adopting different ways of thinking, perspective building, and developing solutions. Third, the teacher became a mentor rather than an instructor and imparter of knowledge, colearning with the students through the process. Fourth, students were invited into complex and dynamic ways of thinking that operate beyond an individual perspective. They had to learn to listen, feel, resonate, and cooperate, helping them see the different interacting parts of the system and to develop core systems thinking skills such as dynamics, operational thinking, and interdependencies.

The Green School. Disrupting conventional perspectives and structures that are often assumed to be necessary for students to develop the core academic competencies, the Green School (https://www.greenschool.org/) aims to create a community of learners who are driven to do what they 
can to contribute to making the world a sustainable place. The school takes a holistic, student-guided approach, integrates with the local and broader community, and incorporates entrepreneurial learning within a wall-less natural environment. The school was founded in 2008 in Bali, Indonesia, with additional campuses recently opening in New Zealand, South Africa, and Mexico. Despite the lack of focus on grades and standardised testing, students have gone on to study at the best universities in the world, create lasting change in their communities, and are becoming inspiring changemakers of the future.

The school is underpinned by a culture of learning, with activities, structures, and approaches centred around the specific needs of the individual learner. Decisions and processes are underpinned by a strong sense of core values, captured by the acronym I-RESPECT: integrity, responsibility, empathy, sustainability, peace, equality, community, and trust. These values give rise to pedagogy that aims to be REAL: Relationship centred and holistic, Experiential and evolving, Authentic and interconnected, and Local to global. Through the REAL learning principles, students can authentically grow and nurture their values, skills, and competencies to support systems transformation across the self, the school, their community, and society. It is assumed that each student brings their own strengths and needs, which educators attune and adjust to. Focus is placed more on how a young person learns rather than what the young person learns. While not explicitly acknowledged, wellbeing is embedded at the heart of the community, starting with the individual, but also outward-facing, inspiring students to do what they can to support the wellbeing of others, the community, and the environment. This outward-facing, systems informed perspective results in life-long learners who make valuable contributions to solving social and ecological challenges.

Lumineer Academy. Based in Victoria, Australia, Lumineer Academy (https://www.lumineer.edu.au/) prides itself on having no uniforms, classrooms, grades, or homework. Its vision is to nurture students to be prepared for any version of the future world, and to be highly capable and compassionate builders of that world. Lumineer Academy harnesses both systems thinking and inquiry learning as core to helping its students be as fluent in emotional intelligence as in cognitive intelligence, supporting them to think independently and originally, and developing the skills with which they can architect this world ethically and compassionately. Lumineer offers Learning Explorations, which are numerous project deliverables that result in novel product invention or innovative services for real-world audiences. All experiences are supported by carefully constructed curriculum and learning explorations, which unify the fundamental prerequisites of learning and nurture 
relationships, drawing upon cutting-edge cognitive, social and emotional tools, interconnected frameworks of delivery, and pedagogical approaches with educational philosophies. Embracing systems dynamics and multiple perspectives, leaning into these systems principles allows a style of learning that enables students to thrive in a world that is constantly in the process of being invented.

The PLACE. The Parent-Led and Community Education initiative (PLACE) in the UK (https://www.parentkind.org.uk/) merges homeschooling and mainstream schools as it seeks to reincorporate the local community as an integral element for understanding, learning, growth, and development. In the initiative, students engage with parents and members of the community, and together they explore real-world issues and learn foundational skills to problem solve and form solutions, ultimately trying to be part of the solution. The PLACE incorporates understanding of interdependencies; this awareness in turn encourages learners to develop personal agency and allows personalised learning to be co-created with communities (Global Education Leaders' Program, 2013).

The Hole in the Wall. The systems sciences suggest that self-organisation arises when local interactions between smaller component parts of an initially disordered system begin to coordinate and work together resulting in decentralised distribution (von Bertalannfy, 1968). As each individual plays their own role well within and interconnected with the whole, the system functions effectively. The Hole in the Wall (https://www.hole-in-the-wall.com/) experiment in New Dehli, India brought this to life. Local businessmen placed a computer into a wall in the slums of New Dehli, which could be accessed by anyone in the community. There was no instruction, but children in the area were drawn to the computer, exploring and learning, and working together. Over time, they managed to make sense of something they had never seen before and were able to engage with self-directed, peer-to-peer learning, and to identify ways to make the computer function. The children spread that knowledge to others, resulting in decentralised distribution of learning. The Hole in the Wall illustrates how an emergent learning experience can result in both accomplishment and deeper levels of engagement with learning (Global Education Leaders' Program, 2013; Senge et al., 2012).

\section{Implications}

Effective implementation in education is a systems matter (Goleman \& Senge, 2014). Adopting a SIPE perspective helps us to think beyond the self, 
moving towards a holistic picture of school, society, and the world. Effective implementation requires more than just the coordination of activities and aims across a large group of people or offering programs or activities centred around specific outcomes, but to consider the infrastructures that might be needed within, across, and between each element of the system to allow new possibilities to emerge. For instance, you might adopt a well thought-out and contextually applicable curriculum. In addition, you support teachers with upskilling and training of the delivery, so that they feel confident in its delivery. Increasingly, schools are incorporating coaching models within schools, including teacher-student, peer-peer, and colleaguecolleague combinations, to help translate key skills of facilitating positive education into what are sometimes challenging classroom contexts (Green $\&$ Norrish, 2013). Strong relationships and networks among staff need to be cultivated, with infrastructures that support and are further strengthened through alignment of the school's values, priorities, actions, combined with the understanding that schools are learning societies.

As the complexities are explicitly acknowledged, it becomes clear that even as positive education approaches can add value, they are not a silver bullet. Much will impact what practices and approaches work, for who, and under what conditions. Simple activities alone will only have short-term effects unless they are embedded within the explicit culture of the school (e.g., slogans, physical setting, ceremonies) as well as the invisible aspects of the school (e.g., underlying values, attitudes, feelings, norms). Change efforts need to acknowledge the sheer complexities of the school environment and recognise that change often takes considerable amounts of time and continued effort. School leadership and teachers need to be committed to the long haul, or else positive education will simply be another passing fad, resulting in activity rather than impact.

Indeed, education has been famous for fads and unsuccessful attempts with quick fixes. There is often deep fragmentation of the educational process, and too often we fail to capture the imagination and commitment of the learner in the way any real learning process must (Senge, 1995). SIPE attempts to redress this, such that each learner can discover and develop to their full potential, contributing not only to their own growth and development, but also with the passion, inspiration, and capability to positively impact the world. Qualities of wholeness relate to every aspect of our lives, including work, school, home, and beyond with more information, intense interdependencies, and relentless change. This is why Senge and others see an enormous need to integrate systems thinking as a foundation for education for young people (Global Education Leaders' Program, 2013; Goleman \& Senge, 2014; 
Senge, 1995; Senge et al., 2012). If positive education is going to become an integral part of education, then it likewise needs to integrate systems thinking into the foundation of its theory, research, and practice.

A challenge is the understanding of the word "system" itself. The word has been popularised without a fundamental understanding of its implications, to the point where everything is a "system", but nothing is really treated as one (Betts, 1992). From our experience, people often think of systems in terms of Bronfenbrenner's (1994) socioecological model, in which the individual is embedded with a series of levels (i.e., the microsystem, mesosystem, exosystem, macrosystem, and chronosystem). From this perspective, a school might take a systems approach by including not only students in positive education efforts, but also incorporating other stakeholders such as teachers, staff, leadership, and at times parents. While expanding beyond the individual is part of a systems informed approach, it is insufficient. A SIPE perspective goes beyond simply looking at the layers in which a person resides, impacts, and impacts upon, to incorporate other systems elements such as inter-dependencies, dynamics, complexity, adaptation, and emergence.

A SIPE perspective calls us to pause before taking action, taking time to listen widely and deeply. Positive education approaches often begin with decisions by leaders, who determine the appropriate frameworks, curricula, activities, and assessment approaches. Yet this can prioritise the perspective of the leaders, which might not align with the perspectives and needs of other shareholders within the system, including students, teachers, non-teaching staff, parents, and the local community. This is often accentuated by bringing in "experts" to guide the process: outsiders who lack an understanding of the specific context (and often have competing economic interests). SIPE emphasises the need to listen widely to diverse perspectives. Rather than moving immediately to action, implementors should take time to hear different perspectives, using a variety of tools or strategies. For instance, some schools have incorporated appreciative inquiry into their change approaches, providing an opportunity to give voice to and value multiple perspectives (e.g., Waters \& White, 2015). Others have used participatory action research approaches to incorporate student voice into positive education efforts (Halliday, Kern, Garrett, \& Turnbull, 2019).

SIPE also invites educators to listen deeply. What is really needed in the system? Are we creating content to fulfill our own need to be useful, or the content or space that people really need? For instance, as the COVID19 pandemic unfolded and people worldwide were forced into lockdown, many across the positive psychology community responded by writing blogs, creating podcasts, sharing free resources, offering webinars, and more, all 
focused on ways to support wellbeing. These were important as people grappled with the changes thrust upon them. There are times to build people up, temporarily helping them feel good, be productive, and keep functioning. At other times, there is a need to give space to reflect, grieve, and make sense of one's experiences. What are the needs of students, teachers, and leaders? Before action, we need to pause and consider what action is really needed and what will be most useful—not only in the moment, but in the longer term. At times, the greatest growth and healing occurs through times of struggle and pain.

A SIPE perspective suggests the need to embrace simplexity. As we have indicated throughout this chapter, human systems generally and schools in particular are complex. And yet as humans, we desire simplicity. This is why we like simple interventions so much-do this and you will feel or function better. The key is to find simple ways to act, while holding on to the complex nature of our schools. This is what learning systems are all about. We need to flexibly zoom into specific approaches and issues at specific times, and then zoom out to consider where our actions sit within the broader scheme. For instance, using a wellbeing assessment, we might identify that a particular year level is struggling with developing social relationships, whereas another year level has high levels of anxiety. These give us specific areas in which to incorporate programs to provide students with the skills and competencies they need. But we need to see this program within the broader course of the students' development. As a result, we might flexibly draw upon a range of resources, programs, curricula, and areas to meet and support the developing needs of our learners individually and collectively.

From a SIPE perspective, values are at the heart of all that we do. Wellbeing is not value-free. Attempts to define the good life are contingent upon the values defined by the context and systems that we are embedded within (Alexandrova, 2017; Kern et al., 2020). Wellbeing arises from living aligned with one's values, which are constantly defined by, negotiated, and embodied by people within and across our systems. Wellbeing occurs by living according to values that are established, defined, and maintained by communities (Kern et al., 2020). Schools commonly have a defined set of values (Allen, Kern, Vella-Brodrick, \& Waters, 2018). To what extent do these reflect the lived values of members of the school community? Where is wellbeing situated within those values? Positive education efforts should align with and stem from these values.

A SIPE perspective emphasises the shared and collective responsibility of wellbeing. As schools, it is our responsibility to do what we can to create environments that support our school community. But people need to accept responsibility for their own wellbeing, to the best that they are able. That 
means equipping them with the skills and resources that they need, giving them opportunities for practice, and permission for autonomous behaviour.

Finally, SIPE challenges us to consider our role in creating positive change within our school communities. What is your role?

- Informers: How can you identify the best information that you can disseminate and share with others? What are the best means to do so, in ways that are cognizant of and respectful of the specific culture?

- Visionaries: How can you identify what is needed moving forward, not what you need?

- Researchers: How can you study human experiences in informative ways, while acknowledging your own biases? How can you more directly integrate with practice, while maintaining necessary rigour? How can you design your studies to move beyond simple linear relationships to better incorporate complexity and dynamics of individual and collective experiences?

- Practitioners: What evidence is most useful? When is the research useful, and when does it need to be adapted to the context? How can you feed that back to researchers?

- For us all: How can we extend beyond our desire for silver bullets and quick fixes to fully embrace the complexity of human experience?

\section{Conclusion}

Education systems are complex, with multiple dynamic, interconnecting parts that form evolving interdependent relationships. For positive education to be more than a passing fad, this complexity must be acknowledged. For positive education to be truly effective and sustainable, it is critical that we take a systems approach to education. Creating positive change is challenging. Too often, school change initiatives view change through the lens of individual parts, rather than seeing the whole living system. Education systems are comprised of many interconnected elements, including, students, teachers, parents, curriculum, legislation, policy, funding, and buildings. These are each connected together with a range of other related elements, including perceptions, priorities, norms, beliefs, and values.

We are living through unprecedented times. In many ways, the world is ready for the SIPE perspective. Through the COVID-19 pandemic, schools and workplaces that prioritised wellbeing prior to the pandemic have travelled better than those with dysfunctional cultures, but this becomes even more 
challenging as we embrace the complexity of life. The challenge is to move beyond the appeal of simple approaches and quick fixes, to fully wrestle with and incorporate the messiness and magic of complexity, inspiring the hopes, insights, and potential of current and future generations.

\section{References}

Alexandrova, A. (2017). A philosophy for the science of well-being. Oxford University Press.

Allen, K., Kern, M. L., Vella-Brodrick, D., \& Waters, L. (2018). Understanding the priorities of Australian secondary schools through an analysis of their mission and vision statements. Educational Administration Quarterly, 54, 249-274. https:// doi.org/10.1177/0013161X18758655.

Allison, L., Waters, L., \& Kern, M. L. (2020). Flourishing classrooms: Applying a systems-informed approach to positive education. Contemporary School Psychology. https://doi.org/10.1007/s40688-019-00267-8.

Benson, P. L., \& Scales, P. C. (2009). The definition and preliminary measurement of thriving in adolescence. The Journal of Positive Psychology, 4, 85-104. https:// doi.org/10.1080/17439760802399240.

Betts, F. (1992). How systems thinking applies to education. Educational Leadership, $50,38-41$.

Biswas-Diener, R., Diener, E., \& Lyubchik, N. (2015). Wellbeing in Bhutan. International Journal of Wellbeing, 5(2), 1-13. https://doi.org/10.5502/ijw.v5i2.1.

Bronfenbrenner, U. (1994). Ecological models of human development. In T. Husen $\&$ T. N. Postlethwaite (Eds.), International encyclopedia of education (2nd ed., Vol. 3, pp. 1643-1647). Oxford: Pergamon/Elsevier.

Buchanan, A., \& Kern, M. L. (2017). The benefit mindset: The psychology of contribution and everyday leadership. International Journal of Wellbeing, 7, 1-11. https://doi.org/10.5502/ijw.v7i1.538.

Buckler, C., \& Creech, H. (2014). Shaping the future we want: UN Decade of Education for Sustainable Development (Final Report). UNESCO.

Durlak, J. A., Weissberg, R. P., Dymnicki, A. B., Taylor, R. D., \& Schellinger, K. B. (2011). The impact of enhancing students' social and emotional learning: A meta-analysis of school-based universal interventions. Child Development, 82, 405-432. https://doi.org/10.1111/j.1467-8624.2010.01564.x.

Fadel, C., Bialik, M., \& Trilling, B. (2015). Four-dimensional education: The competencies learners need to succeed. Boston, MA: Center for Curriculum Redesign.

Garmston, R., \& Wellman, B. (1995). Adaptive schools in a quantum universe. Educational Leadership, 52, 6-12.

Global Education Leaders' Program. (2013). Redesigning education: Shaping learning systems around the globe. Booktrope. 
Goleman, D., \& Senge, P. (2014). The triple focus: A new approach to education. Florence, MA: More than Sound.

Green, L. S., \& Norrish, J. M. (2013). Enhancing well-being in adolescents: Positive psychology and coaching psychology interventions in schools. In C. Proctor \& A. Linley (Eds.), Research, applications, and interventions for children and adolescents (pp. 211-222). Dordrecht: Springer.

Halliday, A. J., Kern, M. L., Garrett, D. K., \& Turnbull, D. A. (2019). The student voice in wellbeing: A case study of participatory action research in positive education. Educational Action Research, 27, 173-196. https://doi.org/10.1080/ 09650792.2018 .1436079 .

Harrison, E. K., Quick, A., Abdallah, S., Ruggeri, K., Garcia Garzon, G., Maguire, Á., ..., Zwiener, N. (2016). Looking into the wellbeing kaleidoscope: Results from the European social survey. New Economics Foundation. https://www.europeans ocialsurvey.org/docs/about/Looking_through_wellbeing_kaleidoscope.pdf.

Hieronymi, A. (2013). Understanding systems science: A visual and integrative approach. Systems Research and Behavioral Science, 30, 580-595. https://doi.org/ $10.1002 /$ sres. 2215.

Jackson, M. C. (2003). Systems thinking: Creative holism for managers. West Sussex, UK: Wiley.

Kern, M. L., Park, N., Peterson, C., \& Romer, D. (2017). The positive perspective on youth development. In Treating and preventing adolescent mental disorders: What we know and what we don't know (Vol. 2). In D. Romer \& The Commission Chairs of the Adolescent Mental Health Initiative of the Annenberg Public Policy Center and the Sunnylands Trust (pp. 543-567). New York: Oxford University Press.

Kern, M. L., Williams, P., Spong, C., Colla, R., Sharma, K., Downie, A., Taylor, J. A., Sharp, S., Siokou, C., \& Oades, L. G. (2020). Systems informed positive psychology. Journal of Positive Psychology, 15, 705--715. https://doi.org/10.1080/ 17439760.2019.1639799.

Larson, R. W. (2000). Toward a psychology of positive youth development. American Psychologist, 55, 170-183. https://doi.org/10.1037/0003-066X.55.1.170.

Lerner, J. V., Phelps, E., Forman, Y., \& Bowers, E. P. (2009). Positive youth development. In R. M. Lerner \& L. Steinberg (Eds.), Handbook of adolescent psychology (Vol. 1, pp. 525-558). Wiley. https://doi.org/10.1002/9780470479193.adlpsy 001016.

Lerner, R. M., Almerigi, J. B., Theokas, C., \& Lerner, J. V. (2005). Positive youth development: A view of the issues. Journal of Early Adolescence, 25, 10-16. https://doi.org/10.1177/0272431604273211.

Meadows, D. H. (2008). Thinking in systems: A primer. Chelsea Green Publishing.

Nguyen, N., \& Bosch, O. (2013). A systems thinking approach to identify leverage points for sustainability: A case study in the Cat Ba Biosphere Reserve, Vietnam. Systems Research and Behavioral Science, 30, 104-115. https://doi.org/10.1002/ sres. 2145 . 
Oberle, E., Domitrovich, C. E., Meyers, D. C., \& Weissberg, R. P. (2016). Establishing systemic social and emotional learning approaches in schools: A framework for schoolwide implementation. Cambridge Journal of Education, 46, 277-297. https://doi.org/10.1080/0305764X.2015.1125450.

Organisation for Economic Co-operation and Development (OECD). (2018). The future of education and skills: Education 2030. OECD. https://www.oecd.org/edu cation/2030/E2030\%20Position\%20Paper\%20(05.04.2018).pdf.

Roth, J. L., \& Brooks-Gunn, J. (2003). What exactly is a youth development program? Answers from research and practice. Applied Developmental Science, 7 , 94-111. https://doi.org/10.1207/S1532480XADS0702_6.

Scharmer, O. (2018). The essentials of theory U: Core principles and applications. Berrett-Koehler Publishers.

Senge, P. (1995). On schools as learning organizations: A conversation with Peter Senge. Educational Leadership, 52(7), 20-23.

Senge, P. M., Cambron-McCabe, N., Lucas, T., Smith, B., \& Dutton, J. (2012). Schools that learn: A fifth discipline fieldbook for educators, parents, and everyone who cares about education. Currency.

Sklad, M., Diekstra, R., Ritter, M. D., Ben, J., \& Gravesteijn, C. (2012). Effectiveness of school-based universal social, emotional, and behavioral programs: Do they enhance students' development in the area of skill, behavior, and adjustment? Psychology in the Schools, 49(9), 892-909. https://doi.org/10.1002/pits. 21641.

Slemp, G. R., Chin, T. C., Kern, M. L., Siokou, C., Loton, D., Oades, L. G., ..., Waters, L. (2017). Positive education in Australia: Practice, measurement, and future directions. In E. Fryenberg, A. J. Martin, \& R. J. Collie (Eds.), Social and emotional learning in Australia and the Asia Pacific (pp. 101-122). Singapore: Springer. https://doi.org/10.1007/978-981-10-3394-0_6.

Spencer, M. B. (1995). Old issues and new theorizing about African-American youth: A phenomenological variant of ecological systems theory. In R. L. Taylor (Ed.), Black youth: Perspectives on their status in the United States (pp. 37-69). Westport, CT: Praeger.

Spencer, M. B., Dupree, D., \& Hartmann, T. (1997). A phenomenological variant of ecological systems theory (PVEST): A self-organization perspective in context. Development and Psychopathology, 9, 817-833. https://doi.org/10.1017/S09545 79497001454.

Swanson, D. P., Cunningham, M., Youngblood, J., II., \& Spencer, M. B. (2008). Racial identity development during childhood. In H. A. Neville, B. B. Tynes, \& S. O. Utsey (Eds.), Handbook of African American psychology (pp. 269-281). Thousand Oaks, CA: Sage.

Vella, S., Oades, L., \& Crowe, T. (2011). The role of the coach in facilitating positive youth development: Moving from theory to practice. Journal of Applied Sport Psychology, 23, 33-48.

von Bertalannfy, L. (1968). General systems theory. New York: Brazillier. 
Waters, L. E., \& White, M. A. (2015). Case study of a school wellbeing initiative: Using appreciative inquiry to support positive change. International Journal of Wellbeing, 5(1), 19-32. https://doi.org/10.5502/ijw.v5i1.2.

White, M., \& Kern, M. L. (2018). Positive education: Learning and teaching for wellbeing and academic mastery. International Journal of Wellbeing, 8(1). https:// doi.org/10.5502/ijw.v8i1.588.

Open Access This chapter is licensed under the terms of the Creative Commons Attribution 4.0 International License (http://creativecommons.org/licenses/by/4.0/), which permits use, sharing, adaptation, distribution and reproduction in any medium or format, as long as you give appropriate credit to the original author(s) and the source, provide a link to the Creative Commons license and indicate if changes were made.

The images or other third party material in this chapter are included in the chapter's Creative Commons license, unless indicated otherwise in a credit line to the material. If material is not included in the chapter's Creative Commons license and your intended use is not permitted by statutory regulation or exceeds the permitted use, you will need to obtain permission directly from the copyright holder.

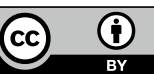

